\title{
Student-Generated Interview Podcasts: An Assignment Template
}

\author{
Clarke Mathany \& Jason Dodd \\ St. Lawrence College
}

DOI: $10.22329 /$ celt.v11i0.4971

Podcast assignments in higher education foster students' deep engagement in course content, knowledge construction, technical skills, and problem-solving abilities. We designed a podcast assignment in a First Year Seminar course based on student-led interviews comparing theoretical concepts to lived experiences of the interviewees. Students were guided through four distinct stages of the assignment and reported that they valued the assignment and felt it supported their learning. Instructors felt that the assignment allowed students to achieve learning outcomes, improve oral communication skills, and engage with course content. We provide a template with timelines for podcast assignments, along with suggestions for implementation.

Dans l'enseignement supérieur, les devoirs consistant à créer des baladodiffusions favorisent la consolidation des connaissances, l'investissement des étudiants dans la matière des cours, ainsi que l'acquisition de compétences techniques et d'aptitudes à la résolution de problèmes. Dans un séminaire de première année, nous avons conçu un devoir de ce type. Les étudiants devaient effectuer des entrevues, puis comparer l'expérience vécue des personnes interviewées à des concepts théoriques. Ils recevaient des consignes tout au long des quatre différentes étapes du projet. Ils ont exprimé des opinions positives au sujet de ce devoir qui, selon eux, a contribué à leur apprentissage. Les enseignants ont jugé que cette tâche avait permis aux étudiants d'accomplir des résultats dans leur apprentissage, d'améliorer leurs compétences en communication orale et de s'investir dans la matière du cours. Nous présentons un modèle de devoir de baladodiffusion comprenant un échéancier, ainsi que des suggestions pour sa mise en ouvre.

ssociated with the increase of mobile
technology and the number podcasts
available, some higher education instructors have begun to include podcasts as a component of their courses. A variety of instructional strategies using podcasts have been implemented including: (1) recording lecture content for further review; (2) providing supplemental materials for students to engage outside of instructional time (having students listen to popular culture podcasts that support knowledge translation and acquisition of the topic); and (3) providing a preview for upcoming topics prior to a lecture (O'Bannon, Lubke, Beard, \& Britt, 2011). Podcasts have many educational benefits, including bringing in expert voices that may otherwise be missing within a classroom (Vatovec \& Balser, 2009), encouraging students to make connections to real-life examples (Moryl, 2013), and providing students with increased flexibility and 
control over when and how they learn (Popova \& Edirisingha, 2010).

In addition to having students consume podcasts to support learning, instructors have also reported using student-generated podcasts as a form of student assessment. Nie, Cashmore, and Cane (2008) argue that student-created podcasts support the development of critical thinking skills such as taking a critical stance on a topic, drawing connections between various topics, encouraging deep engagement with content, and supporting independent thought and work. If a podcast assignment allows students to articulate a position or information on knowledge they have constructed, the public sharing of this work provides the additional benefits of exposing other students in the class to a variety of opinions and giving instructors a clear sense of how students are constructing and linking arguments. In addition to these benefits, assigning podcasts as group projects can encourage collaborative discourse and reinforce the sociocognitive benefits of knowledge construction (Lee, McLoughlin, \& Chan, 2008).

Studies focusing on individual classes that employ student-generated podcasts have outlined further benefits to student learning. Bartle, Longnecker, and Pegrum (2010) describe how students develop key graduate attributes and an understanding of content knowledge by creating three-minute podcasts on foundational chemistry topics for a small assignment in a first-year chemistry class. Within music education, Bolden (2013) describes an assignment that required students to create a documentary combining their own narratives with significant music pieces that have impacted their lives. The authors note that completing this documentary podcast assignment supported students' development of communication, self-expression, creativity, and reflection abilities. Similarly, Armstrong, Tucker, and Massad (2009) share an assessment case in which students worked in groups to create a podcast from an interview with a business expert. Student feedback on the assignment suggests that the podcast assignment supported student development toward specific outcomes of their business program including: (1) understanding of business fundamentals; (2) development of critical thinking skills; (3) enhancement of ethical, interpersonal, communication, and team skills; and (4) development of technology skills.

Persuaded by these podcast case studies and the success they demonstrate in encouraging students to construct knowledge and share ideas publicly within a modern medium, we designed a podcast assignment that built on similar principles. The primary goals of this assignment were to foster students' deep engagement in course content, support knowledge construction, such as drawing connections between topics and real life experiences, and develop technical skills. In this paper, we describe the studentgenerated podcast assignment used within our course, and we provide an assignment template with timelines for instructors considering implementing a student-generated podcast assignment that requires students to conduct interviews. We also describe our assessment of assignment learning outcomes through a student survey and instructor reflections. The paper concludes with suggestions for instructors considering implementing similar assignments.

\section{Assignment Context}

The student-generated podcast assignment was given as part of a first-year seminar course titled Varsity Athletics: Cost, Culture, and Consequence. The course is part of the University of Guelph First Year Seminars program, which offers interdisciplinary seminars to first-year students enrolled in their first or second semester as an undergraduate student. These First Year Seminars utilize inquiry-based pedagogy and "emphasize student participation, critical thinking, and the development of academic skills" ("What's a First Year Seminar", n.d., para. 3). 
Enrollment in each seminar is capped at 18 students in order to encourage a strong connection to campus instructors and to allow students to build relationships with their colleagues from a wide variety of programs.

Varsity Athletics: Cost, Culture, and Consequence engages students with the complex relationship that intercollegiate athletics play at higher education institutions and in society. Students analyze the financial implications of varsity athletic programs, the skills student-athletes develop, and how athletics can impact campus and community culture. The podcast assignment was given to students after they learned about student development theory and how this theory can be applied to the experience of varsity student-athletes. The assignment requires students to explore aspects of student-athlete development in further detail by conducting and recording an interview with a current varsity student-athlete, coach, or administrator. The intended learning outcomes of this assignment are that students will be able to: (1) contrast the theoretical varsity experience with a practice experience through interviewing a current varsity athlete, coach, or administrator; (2) describe the effect that participation in collegiate athletics has on student-athletes by exploring topics such as employability, citizenship, as well as academic, personal, and leadership development; and (3) conduct and record an interview and edit the audio into a podcast suitable for public consumption. By interviewing a varsity athlete or coach, the podcast assignment allows the students to explore the authentic experience of a student-athlete and perspective on their own development through athletics. The assignment format provides a direct opportunity to develop the student's interviewing and oral communication skills.

The rubric for the assignment divided marks amongst these three outcomes. In alignment with the goals of the First Year Seminar Program, the bulk of the grades were based on the student's demonstration of critical thinking skills, ability to develop and ask thought-provoking questions, and ability to synthesize and analyze the comments provided within the interview. To encourage students to produce a quality product, some marks were associated with the production quality, but these were limited to $15 \%$ of the total assignment grade. The lower weighting of the technical component was explicitly shared with students as a way to reduce anxiety about technical challenges and encourage focus on depth of interview and reflection. To support successful completion of the podcast assignment students were guided through four distinct stages of the assignment: (1) knowledge and skill preparation; (2) organizing and conducting the interview; (3) interview synthesis and postproduction; and (4) peer review and class reflection. What follows is a further description of each of these assignment stages.

\section{Stage 1: Knowledge and Skill Preparation}

This stage focused on providing students with the opportunity to understand the context of the assignment and obtain foundational knowledge and skills required to develop a podcast. In this case, students read articles and participated in classroom discussions regarding student development theory and student-athlete development in higher education contexts. The aim of these learning activities was to provide students with knowledge and resources on the theories they would base their interviews and podcasts on.

Concurrently, we provided students opportunities to begin developing the critical thinking skills required to complete the assignment. Students listened to podcasts and participated in discussions regarding effective knowledge translation using this medium. Additionally, effective interviewing skills were introduced through a series of resources and classroom activities. During class, 
students had an opportunity to practice developing and asking open-ended and follow-up questions to encourage further reflection by an interviewee. Through guided self-reflective activities, students considered their strengths and weaknesses as interviewers during these in-class mock interviews. In this preparation stage, students were provided an opportunity to practice recoding and editing audio. Students had access to a "Podcasting Library Guide" created by a Digital Media Librarian at our institution as reference guide to downloading, recording, and editing audio (Parlette-Stewart, 2017). Students were encouraged to use Audacity as an audio-editing software. To resolve last minute audio editing questions, one month before the assignment was due, 60-minutes of class time was dedicated for the Digital Media Librarian to deliver a workshop that walked students through the basics of Audacity. In this workshop, students downloaded the software, imported a basic recording, and practiced using common editing features such as trimming, mixing, and balancing.

\section{Stage 2: Organizing and Conducting the Interview}

In this stage, students independently researched and contacted potential interviewees to set up an interview. With an interviewee confirmed students were expected to develop engaging, appropriate, and in-depth interview and follow-up questions that aligned with the experiences of the student-athlete, coach, or administrator they were interviewing. Students had access to a variety of recording options including borrowing a digital voice recorder from the instructors, recording directly onto their laptop within Audacity, or using one of the many free audiorecording apps available on their computer, smartphone, or tablet.

\section{Stage 3: Interview Synthesis and Post- production}

This stage of the assignment included two distinct segments directly related to the assignment outcomes: (1) comparing theoretical versus practical studentathlete development, and (2) applying technical skills to prepare a sound final podcast product. Students were required to listen to the interview and consider what key knowledge the interviewee shared. They were then asked to compare how the athlete's own experiences related to theoretical perspectives discussed in class. It is here that students were encouraged to move beyond a rote reiteration of what the interviewee said and instead analyze the discussion to make connections back to the course material. Their reflections and interpretations were to be captured in an audio format that could be spliced into the audio interview as an introduction, conclusion, or with appropriate commentary throughout the podcast.

Additionally, students developed a final production of the interview in this stage of the assignment. Applying many of the audio editing skills learned during Stage 1 of the assignment, students worked to create the final ten-minute product with professional sound quality that supported their arguments and claims. One week before the due date, 60 minutes of one class was set aside for students to collaboratively share their sound editing knowledge and work together to solve audio quality challenges.

\section{Stage 4: Peer Review and Class Reflection}

Students uploaded a copy of their final podcast to SoundCloud for it to be shared publicly with classmates, stakeholders in the Department of Athletics, and others interested in this topic. The public dissemination of the work was accompanied by a peer review activity in which students listened to 
three of their colleagues' podcasts for two distinct purposes. First, the students provide graded peer feedback on the assignment outcomes to enhance the volume of feedback students receive on their completed podcast. Second, students were expected to capture common themes identified across the various podcasts and bring those to a larger classroom

Table 1

Template for Podcast Assignment Activities and Timeline

\begin{tabular}{|c|c|c|}
\hline Assignment stage & $\begin{array}{l}\text { Class time } \\
\text { required }\end{array}$ & Key activities \\
\hline \multirow{4}{*}{$\begin{array}{l}\text { Knowledge and } \\
\text { skill preparation }\end{array}$} & 10 minutes & Theories related to podcast assignment introduced \\
\hline & - & $\begin{array}{l}\text { Homework assignment to listen to podcasts and identify strengths } \\
\text { and weaknesses of knowledge translation }\end{array}$ \\
\hline & 20 minutes & Introduce and rehearse interview skills \\
\hline & 60 minutes & $\begin{array}{l}60 \text {-minute in-class session with Digital Media Librarian to support } \\
\text { students in downloading audio-editing software and conducting } \\
\text { basic sound editing tasks }\end{array}$ \\
\hline \multirow{3}{*}{$\begin{array}{l}\text { Organizing and } \\
\text { conducting the } \\
\text { interview }\end{array}$} & - & $\begin{array}{l}\text { Set up interview time with interviewee; ensure interviewee will } \\
\text { provide consent for public dissemination of podcast }\end{array}$ \\
\hline & - & $\begin{array}{l}\text { Research interviewee and generate list of interview questions and } \\
\text { prompts to explore an interesting interview angle related to course } \\
\text { topic }\end{array}$ \\
\hline & - & Conduct and record interview \\
\hline \multirow{3}{*}{$\begin{array}{l}\text { Interview } \\
\text { synthesis and } \\
\text { post-production }\end{array}$} & - & $\begin{array}{l}\text { Edit content of interview to focus most relevant and engaging } \\
\text { aspects of conversation }\end{array}$ \\
\hline & - & $\begin{array}{l}\text { Add introduction and conclusion to support discussion and } \\
\text { highlight key themes and topics discussed }\end{array}$ \\
\hline & 60 minutes & Edit audio to enhance sound quality with support from peers \\
\hline Submit podcast & - & $\begin{array}{l}\text { Submit final podcast to SoundCloud to be shared with class and } \\
\text { Department of Athletics }\end{array}$ \\
\hline
\end{tabular}

discussion. This final classroom discussion was intended to interweave the various individual themes and experiences that the interviews exposed to see prominent trends across the sample of studentathletes interviewed. 


\begin{tabular}{lll}
\hline $\begin{array}{l}\text { Peer review and } \\
\text { class reflection }\end{array}$ & - & Listen to and peer-review classmates' podcasts \\
\cline { 2 - 3 } & 30 minutes & $\begin{array}{l}\text { Identify common themes emerging from podcasts and their } \\
\text { relationship to theories identified in class }\end{array}$ \\
\cline { 2 - 3 } & 10 minutes & Individual reflection on project management and skill development
\end{tabular}

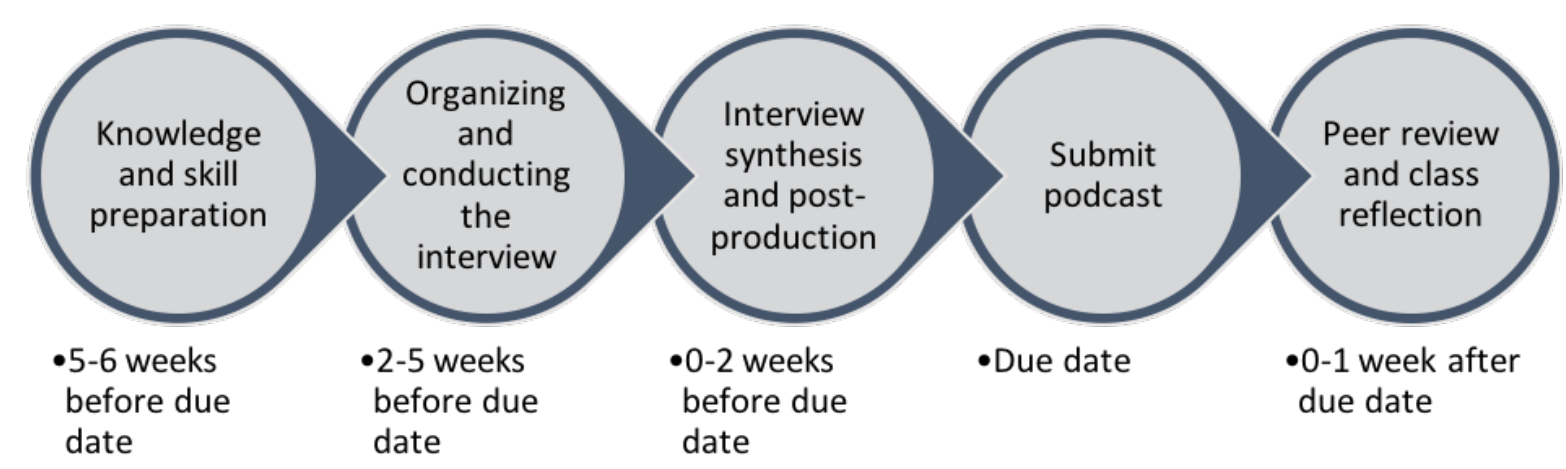

Figure 1

Timeline for Podcast Assignment Activities

\section{Student Achievement of}

\section{Assignment Learning Outcomes}

We conducted a survey asking students from the previous two cohorts of the course to rank and comment on their achievement of assignment learning outcomes. Surveys were conducted after the course was completed and students were made aware that participation was anonymous, optional, and had no impact on their grades in the course. This survey received research ethics approval from the University of Guelph Office of Research.

There was a $37 \%$ response rate $(n=13)$ to the survey. Questions were presented on a 5-point Likert scale explored the understanding and impact, with the following response options: 1 - none at all; 2 - a little ; 3 - a moderate amount; 4 - a lot; 5 - a great deal. Each question directly addressed one of the three assignment learning outcomes, allowing us to assess students' perceived achievement of each outcome. Assignment learning outcomes, survey questions, mean scores, and student comments are presented below.

Regarding our first learning outcome, "Contrast the theoretical varsity experience with a practical experience through interviewing a current varsity athlete, coach, or administrator," students were asked to identify how much the podcast assignment impacted their awareness of: (a) studentathlete identity theory, and (b) realistic studentathlete development. These questions were intended to gauge the success of the assignment in supporting student understanding of both the theory and how it is experienced by varsity athletes. Participants' responses on the 5-point Likert scale indicated that 
these goals were met, as mean responses were: (a) awareness of student-athlete identity theory: $\mathrm{M}=$ $4.38, \mathrm{SD}=0.74$, and (b) awareness of realistic student-athlete development: $\mathrm{M}=4.46, \mathrm{SD}=0.63$. Student responses on the survey supported that talking directly with a student-athlete about their experience had true value on making the theoretical information come to life. One student captured this sentiment, noting that the assignment "helped me learn about how being athletes affects their lives and it was good hearing it first-hand from someone and listening to their stories."

The ability to explore their interviewees' unique experiences in greater depth is captured in the second learning outcome: "Describe the effect that participation in collegiate athletics has on studentathletes by exploring topics such as employability, citizenship, as well as academic, personal, and leadership development." Students were asked to identify how much the podcast assignment impacted their: (a) awareness of the academic challenges that a student-athlete experiences, and (b) awareness of the personal (time management, organization, etc.) challenges that a varsity athlete experiences. Results from the survey suggest that the assignment was a useful experience for students in this regard as the mean scores were: (a) awareness of the academic challenges that a student-athlete experiences: $\mathrm{M}=$ $4.15, \mathrm{SD}=0.77$, and (b) awareness of the personal (time management, organization, etc.) challenges that a varsity athlete experiences: $\mathrm{M}=4.23, \mathrm{SD}=0.97$. Commenting on the perceived learning that took place on this aspect of the assignment, one student noted that in the assignment "I learned a lot about student-athlete experiences, challenges, and how they cope with their overloaded life."

Student interview and audio editing skill development was captured in the third assignment outcome: "Conduct and record an interview and edit the audio into a podcast." Mean Likert scores were somewhat lower for these questions in comparison to the first two outcomes, but indicate that the assignment was helpful in developing in these areas. The mean results of survey questions in this area were: (a) conduct an interview: $\mathrm{M}=3.92, \mathrm{SD}=1.00$, and (b) technically produce a podcast using audio software: $\mathrm{M}=4.15, \mathrm{SD}=0.77$. In providing feedback on conducting an interview a few students commented on the challenge of guiding the conversation to draw out interesting comments from the interviewee. In particular, one student reflected on their own characteristics and how the biggest challenge they experienced during the assignment was "interviewing someone I do not know that well because I am pretty shy which made it a little hard." Comments on learning an audio editing program focused on two somewhat opposing themes of enjoying the unique assignment format and the challenges associated with learning a new software. For example, one student described the assignment as "interesting, although it was a bit difficult to learn the tricks to use the technology to its potential...but it was a fun alternative to a paper for sure." Another student suggested the value of having resources to learn from and that the skill development was valuable: "Having never used Audacity, it was a lot of trial and error. I often looked at the podcast guide and Googled things to figure out the technical side. I wouldn't say it really impacted the experience, it allowed me to develop new skills and wasn't frustrating."

The survey also asked students to rank how valuable they found the podcast assignment, and responses show that students valued the assignment: $\mathrm{M}=4.00, \mathrm{SD}=0.88$, with $77 \%$ of respondents describing the assignment as either very valuable or extremely valuable. The lone respondent who selected a negative response to this question, slightly valuable, cited "struggles with technology" as the primary challenge that they faced.

Finally, our survey explored the students' perspectives on peer feedback, asking them to identify how much the podcast assignment impacted their ability to provide, receive, and implement peer feedback. These means suggest a slightly above 
moderate impact on these skills. Mean responses were: (a) providing peer feedback: $\mathrm{M}=3.31, \mathrm{SD}=$ 1.14 , (b) receiving peer feedback: $\mathrm{M}=3.23, \mathrm{SD}=$ 0.89 , and (c) implementing peer feedback: $\mathrm{M}=3.15$, $\mathrm{SD}=1.17$. While this is a modest positive response from students, from the instructors' perspective the peer collaboration was essential to troubleshoot technical difficulties and enhance overall quality of content and production.

\section{Instructor Reflections}

From our perspective, most students were able to achieve the podcast assignment learning outcomes and progress towards key course learning outcomes. Contrasting theory and practice was a core outcome of both this assignment and the course overall, as outlined by the first learning outcome: "Contrast the theoretical varsity experience with a practical experience through interviewing a current varsity athlete, coach, or administrator." It is significant to note that the podcast assignment enhanced student awareness of the practical experiences of studentathletes and the feedback suggests that conducting and recording an interview allowed for deeper exploration of student-athletes' experiences. Much of our class time early in the semester outlined the theoretical framework regarding student-athlete development, and the podcast provided an opportunity to explore these theories and articulate how they compared to real-life experiences. Similarly, the second learning outcome allowed students to investigate opportunities for development and career plans of student-athletes: "Describe the effect that participation in collegiate athletics has on studentathletes by exploring topics such as employability, citizenship, as well as academic, personal, and leadership development." Many of the interesting findings in this area were captured in natural conversation with student-athletes including the ability to ask follow-up questions. The third assignment learning outcome was focused on student skill development: "Conduct and record an interview and edit the audio into a podcast." In the evolving world of technology, improving technical literacy and audio production skills within the course context provides students with the skills and confidence to create and share their knowledge in new and varied formats. Finally, the podcast assignment provided the opportunity for students to hone their oral communication skills in a new context where they can make changes post-production to improve their voice, word choice, ability to articulate ideas, and ability to synthesize key themes. Students have a series of debates and presentations throughout the course, but the opportunity to edit their oral work to truly capture their arguments was unique to this project and contributed to their overall development.

One of the most valuable aspects of the podcast format is its authenticity; students are responsible for creating a product that is publicly available and must accurately portray the thoughts and feelings of their interviewee. Students seem to have a personal stake in the questions they ask, in making their interview subjects comfortable, and in the quality of production. While some of these skills and outcomes may be achieved through traditional written work or in-class presentations to summarize their interviews and engagement with studentathletes, we feel that there was greater enthusiasm and investment for the podcast format. It is extremely enjoyable to listen to the finished podcasts and hear the commitment in the quality of student work. We are pleased that they took this approach to sharing their academic work and hope that the importance of scholarly communication is impressed upon them throughout their education. While the students report slightly more than a moderate impact of this assignment on their ability to give, receive and implement peer feedback, we feel that the collaboration and support they provided one another in the formative stages of their project were essential to building problem-solving skills and the overall 
quality of the final products. The peer assessment also ensured that they listened to at least three other podcasts to provide a wider audience and broaden their own perspectives on student-athlete development.

The podcast assignment requires careful planning and dedicated class time for the introduction of key skills, collaborative technical troubleshooting, and multiple stages of peer feedback. As outlined above, we dedicated a signification portion of class time to rehearsing interview skills and technical instruction from a Digital Media Librarian. We were very fortunate to access this expertise directly on our campus, which will soon be complimented by a Digital Media Lab to facilitate quality recording and editing. We spent another class working in collaborative groups during the editing phase, for students to listen and provide formative feedback to their peers to enhance the overall quality of the podcasts. While this time investment was significant, we feel it is worthwhile given the novelty and quality of the final product. It is extremely rewarding to listen to the finished podcasts and hear students implement their new interview, communication, and production skills. Grading was also much more enjoyable, as it involved listening to creative podcasts that students were truly invested in creating.

\section{Limitations to Podcast}

\section{Assignments}

Our paper shares the perspectives of two cohorts of students enrolled in an interdisciplinary seminar elective capped at 18 students. It is inherent in the selection of an elective that students are most likely interested in the topic. The students' interest in the course material, and therefore interest in the opportunity to conduct an interview and produce a podcast with a varsity athlete, may contribute to the positive perceptions reported throughout this research. With a $37 \%$ student response rate, it is possible that the feedback captured in this paper represents those students who had a more positive experience with the assignment. Exploring student perceptions of similar assignments in required courses, courses where interview subjects may not be as readily available, or gathering student perception from all students as they submit their final product may elicit more balanced feedback and expose instructors to further considerations for implementing podcast assignments.

The podcast assignment presented challenges in two main ways, both of which require time and effort on behalf of the instructor. First, technical abilities in audio recording and editing is not our expertise. Therefore, addressing technical issues that arise throughout the assignment has the potential to take up considerable time and students could have become frustrated with our novice technical abilities. Second, the assignment design takes class time away from other potential content and opportunities for skill development in other modalities that students will revisit throughout their academic careers, such as writing or traditional presentations. We aim to mitigate this concern with students by addressing the transferable nature of the abilities (i.e. researching for an interview, interviewing participants, synthesizing ideas into a central theme) developed during the assignment and how they can support future research and employment opportunities.

\section{Suggestions for Those Considering Implementing Podcasts}

Our experience developing and implementing a podcast assignment taught us many lessons about how students approach this type of assignment. There 
are many benefits to a new assignment format, including the intended outcomes of student skill development and engaging the athletic community on campus. The podcast assignment encourages students to step outside of their comfort zones, both academically and socially, to build new relationships, apply interview skills, and troubleshoot in a new context. Students have the opportunity to develop time and project management skills by planning ahead to allow for interviewees' busy schedules, production time, and technical issues. As instructors, we support the development of these skills to help students navigate and troubleshoot in their work. There is great value in sharing students' work within and beyond our course, including both athletic and academic communities interested in podcasting or the student-athlete experience.

This assignment is not without its challenges, however. It demands advance planning, deliberate scaffolding of student skill acquisition, and a significant time commitment early on. Our experience was that these efforts pay off in the longer term. Selecting, learning how to use, and developing trouble-shooting abilities within an audio editing software required a significant investment into the assignment. Consultation with the Digital Media Librarian and evaluating software options based on the SECTIONS framework (Bates \& Poole, 2003) led to identifying Audacity as the supported platform. Audacity was selected due to its accessibility as a free software, the strong level of online support forums available for troubleshooting, and the availability of institutional support for the program through our Library. We recognized the need to develop resources to support students throughout podcast production. As a method of learning the technology and identifying potential hurdles students would face in the audio-editing process, we developed podcasts for the course. Developing these podcasts ourselves allowed us to expose students to expert voices within our classroom conversation (i.e. the Athletic Director and Vice-President Student Affairs) and enhanced our ability to troubleshoot some technical challenges without overwhelming the Digital Media Librarian. Not surprisingly, most technical troubleshooting requests arose near the deadline and having some foundational knowledge of the software was valuable as instructors.

The potential impact of students conducting interviews on campus was another consideration we aimed to mitigate prior to the assignment. We connected with the campus's Athletic Director before the assignment to maintain positive relationships with the campus athletic community and in order to ensure the participation of our interviewee population. From our perspective, these challenges were manageable and contributed to the overall quality of student output and reward of sharing their work with our partners.

In the end, our experience with podcasting was rewarding as it required students to apply interview, communication, and technical skills while bringing the theoretical aspects of our course to life. Students reported achieving learning outcomes and an increased perceived value of the assignment format, which validates the time and effort required for instructors to design and implement the podcast assignment. We recommend it to anyone considering an innovative way to assess student learning, and the template described in this paper provides a framework for implementing student-generated interview podcasts into a range of other courses.

\section{References}

Armstrong, G. R., Tucker, J. M., \& Massad, V. J. (2009). Achieving learning goals with student-created podcasts. Decision Sciences Journal of Innovative Education, 7(1), 149154. http://doi.org/10.1111/j.15404609.2008.00209.x

Bartle, E., Longnecker, N., \& Pegrum, M. (2010). Can creating podcasts be a useful assignment 
in a large undergraduate chemistry class? Proceedings of the 16th Uniserve Science Annual Conference, 104-107.

Bates, T., \& Poole, G. (2003). Effective teaching with technology in higher education: Foundations for success. San Francisco, CA: Jossey-Bass.

Bolden, B. (2013). Learner-created podcasts: Students' stories with music. Music Educators Journal, 100(1), 75-80. http://doi.org/10.1177/002743211349375 7

Lee, M. J. W., McLoughlin, C., \& Chan, A. (2008). Talk the talk: Learner-generated podcasts as catalysts for knowledge creation. British Journal of Educational Technology, 39(3), 501-521. http://doi.org/10.1111/j.14678535.2007.00746.x

Moryl, R. (2013). T-shirts, moonshine, and autopsies: Using podcasts to engage undergraduate microeconomics students. International Review of Economics Education, $\quad 13, \quad 67-74$. http://doi.org/10.1016/j.iree.2013.02.001

Nie, M., Cashmore, A., \& Cane, C. (2008). The educational value of student generated podcasts. ALT-C 2008 Research Proceedings, 15-26. Retrieved from http://hdl.handle.net/2381/4396

O'Bannon, B. W., Lubke, J. K., Beard, J. L., \& Britt, V. G. (2011). Using podcasts to replace lecture: Effects on student achievement. Computers and Education, 57(3), 18851892. http://doi.org/10.1016/j.compedu.2011.04. 001

Parlette-Stewart, M. (2017, June 1). LibGuides: Record a podcast: Start here. Retrieved September 26, 2017, from http://guides.lib.uoguelph.ca/Podcasting

Popova, A., \& Edirisingha, P. (2010). How can podcasts support engaging students in learning activities? Procedia - Social and Behavioral Sciences, 2(2), 5034-5038. http://doi.org/10.1016/j.sbspro.2010.03.81 6

Vatovec, C., \& Balser, T. (2009). Podcasts as tools in introductory environmental studies. Journal of Microbiology \& Biology Education, 10(1), 19-24. http://doi.org/10.1128/jmbe.v10.95

What's a First Year Seminar and why should I take one? (n.d.). Retrieved September 26, 2017, from https://www.uoguelph.ca/vpacademic/fys/

\section{Biography}

Clarke Mathany is the Manager of Curriculum Development at St. Lawrence College. Previously, he was an Educational Developer and instructor in the First Year Seminar program at the University of Guelph.

Jason Dodd is a Science Learning Specialist and instructor in the First Year Seminar program at the University of Guelph. 